Relatos de Experiência 


\section{Da construção à utilização de um vídeo didático de Física Térmica}

M arcus Vinicius Pereira*

R esumo: A contribuição do laboratório tradicional para melhoria da aprendizagem de F ísica vem sendo discutida ao longo das últimas décadas. A necessidade de apresentar conceitos físicos através da fenomenologia é indiscutível, em especial na área de F ísica Térmica, mas a realidade da escola atual torna isso quase impossível. I sto remeteà busca por estratégias alternativas, já que a experimentação ao vivo é pouco utilizada na sala de aula. A utilização de vídeos didáticos com características próprias pode contribuir de forma eficiente para o aprendizado dos alunos e para a prática docente, devido à vantagem deotimização detempo eespaço. N este relato se discute o potencial do vídeo como ferramenta didática, a construção de um vídeo que trabalha conceitos da Física Térmica, al ém de recomendações e propostas de utilização do vídeo em sala de aula.

Palavras-chave: V ídeo didático, Física térmica, Tecnologia educacional, Estratégia de ensino-aprendizagem.

A bstract: The contribution of traditional laboratory to learning has been frequently under discussion sincethemiddle of last century. Presenting phenomenology of concepts physics is unarguable, especially in the area of thermal physics, but the reality of Brazilian public schools makes it almost impossible. This refers to the search

\footnotetext{
Professor de Física do Ensino Básico, Técnico e Tecnológico do Instituto Federal de Educação, Ciência e Tecnologia do R io de Janeiro (IFRJ). M estre em Ensino de Ciências e M atemática pelo Centro Federal de Educação Tecnológica Celso Suckow da Fonseca (CEFET-RJ). D outorando em E ducação em Ciências e Saúde (2009) pela U niversidadeF ederal do R io de J aneiro (UFRJ).E-mail: marvin@ marcusvinicius.com
} 
for alternative strategies, since the experimentation in classroom is infrequently. The use of didactic videos with specific characteristics can contribute efficiently for the learning of students and for the teaching practice, due to the advantage of optimizing time and space. The potential of video as a teaching tool is discussed in this report, in addition to the construction of a video that works concepts of thermal physics, as well as recommendations and proposals for use of video in the classroom.

Keywords: Didactic video, Thermal physics, Educational technology, Processes of teaching and learning.

\section{Introdução}

0 projeto de 2005 de Reorientação Curricular do Ensino M édio do Estado do R io deJ aneiro (REORIENTAÇÃO, 2007), distribuído para todas as escolas públicas do estado, propõe uma sequência curricular alternativa para Física em que a Termologia, ao invés da M ecânica, é a primeira área apresentada na primeira série do Ensino Médio.

Independente da área da Física estudada, não há dúvida quanto à necessidade da abordagem experimental no processo de ensino de uma ciência que é essencialmente experimental. Em todos os processos que ocorrem na natureza e nas técnicas o calor está direta ou indiretamente presente. A fenomenologia da Física Térmica tem por base o próprio cotidiano do ser humano através da experiência sensorial que ele adquire desde tenra idade.

0 ensino de Física tem-se realizado frequentementemediantea apresentação de conceitos, leis efórmulas, de forma desarticulada, distanciados do mundo vivido pelos alunos e professores e não só, mas também por isso, vazios de significado (BRASI L, 2000, p. 22).

Porém quando se faz uma reflexão crítica sobre o papel atual das atividades laboratoriais tal como realizadas de maneira equivocada por parte de alguns professores, reconhece-se sua baixa contribuição para a aprendizagem conceitual. D e acordo com 
Lunetta (1998), tanto professores como pesquisadores da área de Ensino de Física vêm questionando a eficiências das atividades laboratoriais na escola básica. Segundo Colinvaux e Barros (2002), os trabalhos de pesquisa ao longo das últimas décadas apontavam a experimentação por parte do aluno como a salvação para o fracasso do ensino de Física, um tipo de "vareta mágica" que faria milagre em relação ao baixo desempenho dos alunos.

D eve-se considerar ainda a falta de tradição escolar no Bra sil em valorizar atividades práticas, que requerem um amplo espectro de habilidades por parte dos estudantes e dos docentes. A quase inexistência do laboratório propriamente dito nas escolas, principalmente públicas, faz com que se pense na realização de demonstrações ao vivo, porém isto acarreta, segundo Pereira, Filipecki e Barros (2005), em gasto de energia considerável com planejamento, organização e montagem da demonstração nas diversas aulas, o que dificulta a manutenção dessa prática ao longo do tempo.

O vídeo é uma estratégia alternativa para apresentação de atividades experimentais, que possibilita a exploração do fenômeno ao dar oportunidade ao professor de discutir os modelos físicos e teóricos, que podem levar o aluno ao observar a demonstração gravada a uma melhor compreensão dos conceitos físicos envolvidos.

N o entanto o potencial do vídeo ainda é pouco explorado. Em geral sua apresentação não é pensada como uma metodologia, mas sim como entretenimento ou em alguns casos mero repetidor da aula tradicional. A escola deve estar apta para aproveitar a relação íntima e intensa que jovens e adultos têm com a produção audiovisual e incorporá-la em suas práticas.

As transformações no campo da comunicação, com a integração das linguagens nos sistemas multimídia na produção de imagens, colocaram a tecnologia do vídeo ao alcance do cidadão comum.

A produção de um vídeo com recursos simples, composto de demonstrações experimentais curtas e com mínimo de locução, pode potencializar parcialmente algumas das habilidades que 
seriam desenvolvidas nas atividades realizadas ao vivo, já que o vídeo também apresenta enfoque fenomenológico, e o professor poderá explorá-lo à medida que trabalha com esse material em suas aulas, de acordo com a necessidade.

\section{0 vídeo didático}

O bservar o comportamento dos jovens em idade escolar, já criados numa convivên cia íntima com os videogames, televisõese computadores, podeser significativo para entender, por um lado, algumas das razões do fracasso da escola atual e, por outro, alguns elementos para uma posśvel superação desse fracasso. (PRETTO, 2005, p. 103)

0 avanço das tecnologias da informação e comunicação (TICS) cria um descompasso à medida que a escola ainda não as incorpora de forma eficaz. Segundo FERRÉS (1996), esse descompasso se deve, em certa medida, às dificuldades dos professores na promoção de mudanças em suas práticas cotidianas.

A tualmente, a tecnologia do vídeo, através dos computadores e das câmeras digitais, está ao alcance do professor motivado, que pode, ao invés de realizar demonstrações em suas aulas, optar pela gravação em vídeo do fenômeno físico que deseja demonstrar.

O uso do vídeo didático, entre outras facilidades, permite rever em ritmo próprio e analisar uma sequência específica de cenas a fim de atingir objetivos previamente estabelecidos. D essa forma, a gravação em vídeo de um fenômeno físico é interessante porque possibilita ao assistente revêlo tantas vezes quantas forem necessárias.

U ma vez bem preparado, um vídeo pode ser reutilizado tanto pelo professor que o desenvolveu quanto por outros professores e alunos, assim como por qualquer pessoa que tenha interesse no assunto caso ele seja disponibilizado na internet. Como exemplo, o site YouTube (Fig. 1) funciona gratuitamente como repositório onde os usuários podem compartilhar vídeos, avaliar, comentar, entre outras ferramentas, e qualquer internauta, 
mesmo não cadastrado, pode assistir. Segundo estatísticas recentes, o Brasil é um dos países com maior número de acessos ao YouTube.

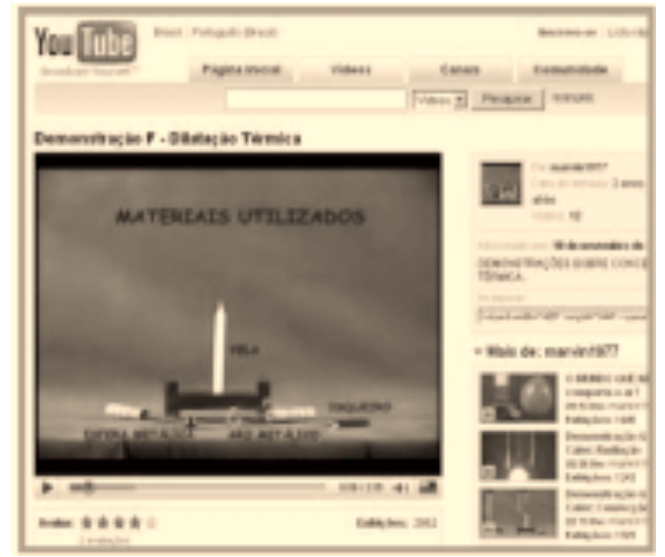

Figura 1: Site youtube exibindo uma demonstração que compõe o vídeo, já acessada 2062 vezes < http://br.youtube.com/ watch?v=jfOV_WgBem4>

U m professor também pode estimular a produção audiovisual independente pelos seus al unos (FIL IPECK I; BARR OS, 1999), através da realização de demonstrações experimentais, documentários, trabalhos de pesquisa, entre outros.

\section{Desenvolvimento do vídeo}

O vídeo foi idealizado como um conjunto de demonstrações experimentais controladas, a serem exibidas com ou sem áudio, com a finalidade de apropriação por parte do professor.

Com a finalidade de estruturar as ideias e os conceitos básicos que norteariam o roteiro do vídeo, fez-se um levantamento bibliográfico de trabalhos acadêmicos que discutem as concepções espontâneas acerca dos conceitos relacionados à Termologia.

U ma versão piloto do vídeo (Fig.2) foi produzida com recursos domésticos ( câmera V H S-C, gravação de forma linear, sem 
recurso de edição e sem áudio), e foi apresentada a um grupo de trinta estudantes a fim de estudar seu efeito.

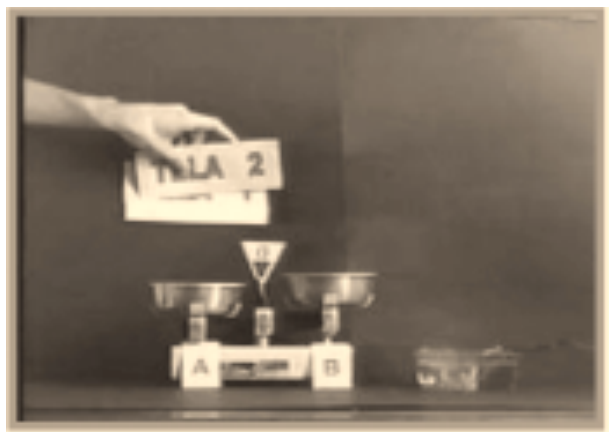

Figura 2: Exemplo de cena da versão piloto

Esta experiência permitiu constatar o potencial de um material didático que dava conta tanto de aspectos pedagógicos, uma vez que trouxe para a sala de aula a fenomenologia, assim como de aspectos motivacionais e disciplinares, pois o grupo assistiu ao vídeo com atenção, interagindo entre eles e com o professor, e preenchendo as fichas solicitadas.

Essa reflexão fez com que se retomasse o processo de produção com melhores recursos (Fig. 3) e novas reflexões, que durou aproximadamente três meses. A edição do vídeo, utilizando o programa de edição não-linear A dobe Premiere, ocorreu nos dois meses subsequentes.

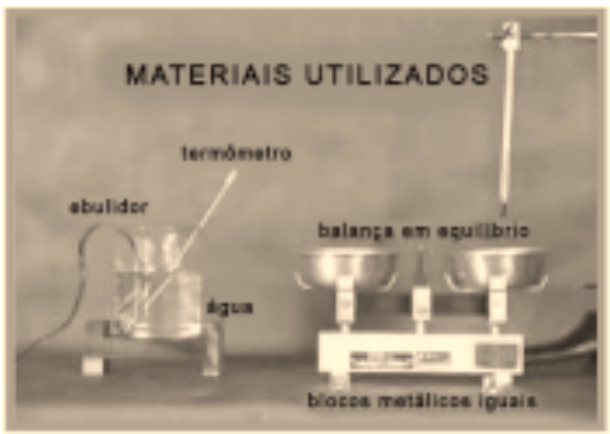

Figura 3: Exemplo de cena da versão final 
O vídeo D emonstraçoes sobre C onceitos de Físca T érmica apresenta características próprias, não comuns à maioria dos vídeos didáticos científicos. Trata-se de um material didático audiovisual com produção focada em sua utilização na sala de aula, composto de um conjunto de demonstrações experimentais de fenômenos simples.

Cada demonstração está relacionada a um conceito básico, e apresenta os seguintes elementos: materiais utilizados; condições da experiência; interações com o sistema. A companhada de uma ficha de registro a ser preenchida pelo aluno, a demonstração tenta fazer com ele seja envolvido em uma estratégia do tipo observação - registro - pergunta - explicação, e assim possa construir ou ressignificar o conceito trabalhado.

D e acordo com a classificação de Ferrés (1996), o vídeo desenvolvido desempenha as funções informativa, motivadora e investigativa no processo de ensino-aprendizagem: informativa, à medida que apresenta um fenômeno real com locução explicativa inicial a cerca dos conceitos envolvidos; motivadora, pois seu desenvolvimento tem como interesse do ato comunicativo o destinatário, ou seja, o aluno; investigativa, já que aproxima e amplia o objeto de estudo para o estudante.

0 vídeo tem duração total de vinte (20) minutos, sendo composto de onze (11) demonstrações curtas (Tab. 1), e com locução resumida para que o professor possa se apossar e utilizar da forma que melhor Ihe convier. Ele encontra-se disponível em $<$ http://br.youtube.com/view_play_list?p =EC1930421F006E $14>$.

\begin{tabular}{|c|c|c|}
\hline CÓDIGO & TÍTULO & DURAÇÃO \\
\hline $\mathrm{A} 1$ & $\begin{array}{c}\text { Natureza do Calor: calor como } \\
\text { matéria }\end{array}$ & 1 min $26 \mathrm{~s}$ \\
\hline $\mathrm{A} 2$ & $\begin{array}{c}\text { Natureza do Calor: calor como } \\
\text { forma de energia }\end{array}$ & 2 min $05 \mathrm{~s}$ \\
\hline $\mathrm{B} 1$ & Temperatura: grandeza intensiva & 0 min $45 \mathrm{~s}$ \\
\hline B2 & $\begin{array}{c}\text { Capacidade térmica: grandeza } \\
\text { extensiva }\end{array}$ & 1 min $58 \mathrm{~s}$ \\
\hline
\end{tabular}




\begin{tabular}{|c|c|c|}
\hline C & Condutores e Isolantes Térmicos & 2 min $20 \mathrm{~s}$ \\
\hline D & Trocas de Calor (I e II) & 1 min $52 \mathrm{~s}$ \\
\hline E & Mudanças de Estado & 2 min $03 \mathrm{~s}$ \\
\hline F & Dilatação Térmica & 1 min $48 \mathrm{~s}$ \\
\hline G1 & Propagação do Calor: Condução & 3 min $05 \mathrm{~s}$ \\
\hline G2 & Propagação do Calor: Convecção & 1 min $52 \mathrm{~s}$ \\
\hline G3 & Propagação do Calor: Radiação & 0 min $40 \mathrm{~s}$ \\
\hline
\end{tabular}

Tabela 1: D emonstrações que compõem o vídeo

Cada demonstração apresenta a seguinte sequência: título; materiais utilizados; condições iniciais; fenômeno demonstrado; e créditos finais. Como exemplo, a Fig. 5 mostra imagens das cenas básicas produzidas para a demonstração $\mathrm{G} 2$.

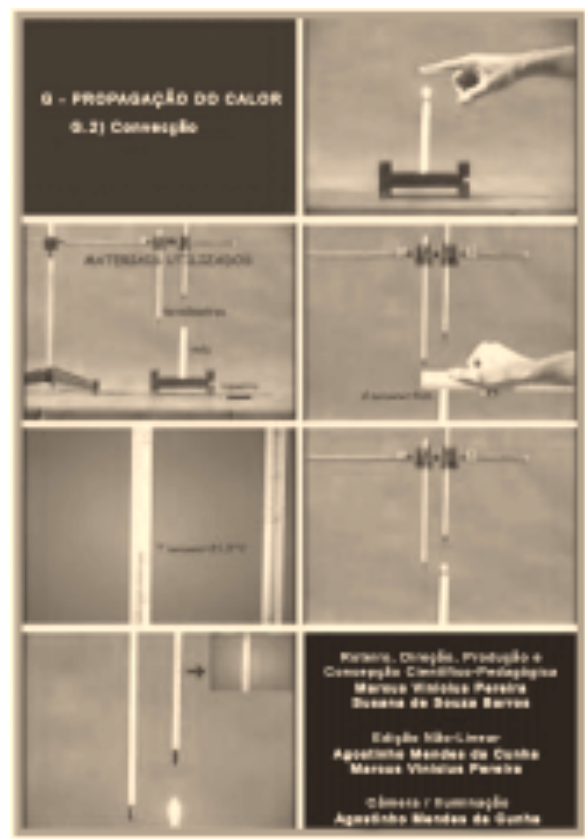

Figura 5: Cenas da demonstração G2 http://br.youtube.com/watch?v=0V 6 _imnbJ J Q 
0 vídeo é acompanhado de um material impresso para o aluno denominado Guia de Acompanhamento do Vídeo, composto de uma capa de apresentação em que constam os créditos do material didático, e o conjunto de Fichas do Aluno. Cada Ficha está associada a uma demonstração e está subdividida em registro programado da observação e perguntas de compreensão conceitual sobre o fenômeno apresentado, visando orientar a observação e identificação das grandezas físicas relevantes e das relações entre elas. As perguntas solicitadas têm como objetivo estimular 0 aluno a pensar sobre o fenômeno, buscar explanações, e fazer inferências baseadas nas informações extraídas da observação.

\section{Aplicação em sala de aula}

O vídeo $\mathrm{D}$ emonstrações sobre Conceitos de Física Térmica foi aplicado como Organizador Prévio Experimental (OPE), que, dentre as características do organizador prévio originalmente proposto por AU SU BEL (1968), trabalha os conceitos em um nível mais alto de generalidade, tendo a função de reativar nos estudantes os conceitos já existentes e os confrontar com os conceitos científicos apresentados nas demonstrações.

$\mathrm{O}$ vídeo foi aplicado durante o período regular de aulas em uma turma do primeiro ano do Ensino M édio Técnico de uma escola pública federal do R io de Janeiro no segundo semestre de 2006.

Com o objetivo de estudar a eficiência da utilização do material como organizador prévio, foram construídos dois instrumentos básicos que foram aplicados em três momentos distintos.

O primeiro instrumento (Anexo I) foi aplicado antes da exibição do vídeo, como Pré-Teste, e após a exibição, como PósTeste. $O$ segundo instrumento, denominado Avaliação Final, foi aplicado ao final da instrução formal da Física Térmica. Tanto o Pré e Pós-Teste como a Avaliação Final são testes compostos, cada 
um, de 10 (dez) questões retiradas ou baseadas, principalmente, nos resultados da literatura da pesquisa em ensino de Física.

A aplicação do Pré-Teste teve por função levantar as dificuldades conceituais dos estudantes, verificando como eles se expressam na escrita através das justificativas dadas às questões. 0 Pós-Teste, idêntico ao Pré, foi aplicado após os alunos interagirem com o vídeo, com o objetivo de estudar o efeito propriamente dito sobre a mudança na linguagem escrita por parte desse grupo de estudantes ao terem de se expressar sobre os mesmos conceitos.

A Avaliação Final apresenta questões relacionadas conceitualmente tanto com as questões do Pré/Pós-Teste, como com as demonstrações que compõem o vídeo.

A Fig. 6 apresenta o cronograma da aplicação, onde cada aula corresponde a um período de 45 minutos. A etapa diagnóstica (aplicação do vídeo) levou duas (2) semanas, ea escolarização (instrução formal) levou dez (10) semanas.

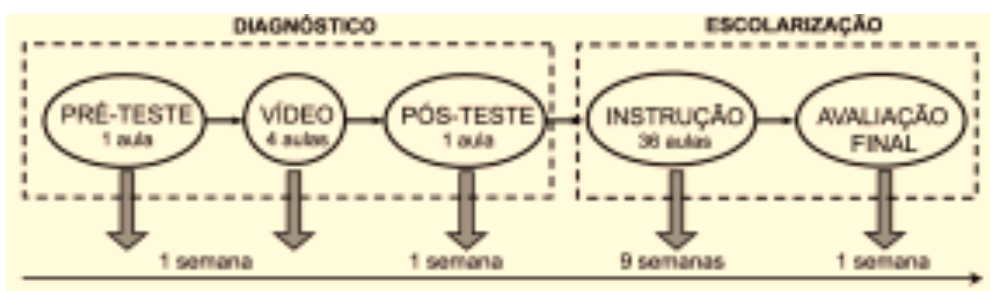

Figura 6: Cronograma do estudo do efeito da aplicação do vídeo

$\mathrm{N}$ a primeira aula, apresentou-se o trabalho a ser desenvolvido, salientando a importância do comprometimento de cada estudante e explicando a metodologia a ser utilizada. Esclareceu-se que o teste seria respondido individualmente, e, até este momento, os alunos sabiam apenas que assistiriam a um vídeo relacionado às questões do teste.

O s alunos foram comunicados pelo professor que nenhuma atividade seria convertida em nota, e, nesse momento, chamou-se a atenção deles para a importância de uma reflexão crítica sobre as questões propostas. A pós a realização do teste, o vídeo 
foi exibido sem pausas na sala de aula utilizando um computador portátil e um projetor digital (data-show).

$\mathrm{N}$ a aula seguinte, o vídeo foi novamente exibido para a turma, desta vez realizando pausas para esclarecer dúvidas dos alunos quanto ao que observavam. N este momento os estudantes estavam em uma das salas de informática da escola (Fig. 7), e foram orientados a utilizarem o computador para assistirem ao vídeo, um aluno em cada máquina, e preencherem de forma sistemática e independente as Fichas do Guia de Acompanhamento do $V$ ídeo, entregue na forma de um livreto impresso para cada um. O laboratório de informática dispunha de computadores de performance básica, e estavam ligados em rede, de forma que o vídeo pôde ser disponibilizado em um diretório comum.

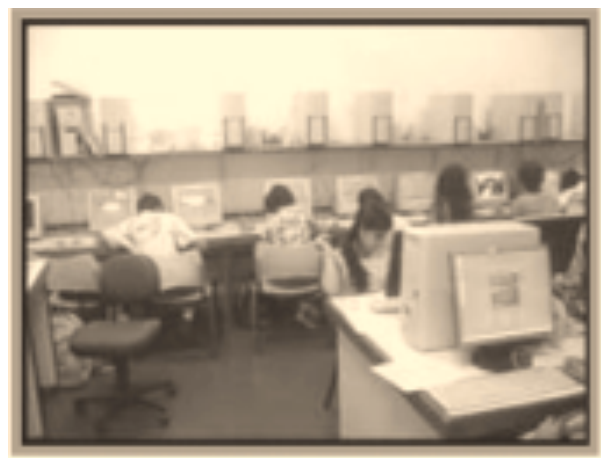

Figura 7: A plicação do vídeo

O s estudantes assistiram às demonstrações quantas vezes precisaram, solicitando o professor à medida que tinham dúvidas. Eles informaram em cada Ficha o número de vezes que repetiram a respectiva demonstração.

O Pós-Teste foi aplicado uma semana após a exibição do vídeo. Solicitou-se, de forma enfática, que os alunos levassem em conta o fato das demonstrações assistidas estarem associadas às questões do teste ao elaborarem suas justificativas.

A etapa referente à E scolarização sucedeu à D iagnóstica. A instrução formal dos conteúdos de Física Térmica aconteceu ao longo de aproximadamente dez (10) semanas, com dois (2) 
encontros semanais de 1h 30 min cada. A exposição do conteúdo pelo professor foi tradicional, com uso de quadro e giz e estudo do livro texto adotado e bibliografia recomendada.

O s dados obtidos com a aplicação dos instrumentos para os conteúdos específicos de cada demonstração encontram-se apresentados no Gráfico 1 abaixo, o que pode indicar o potencial da estratégia do vídeo como auxiliar ao trabalho de construção de conceitos físicos.

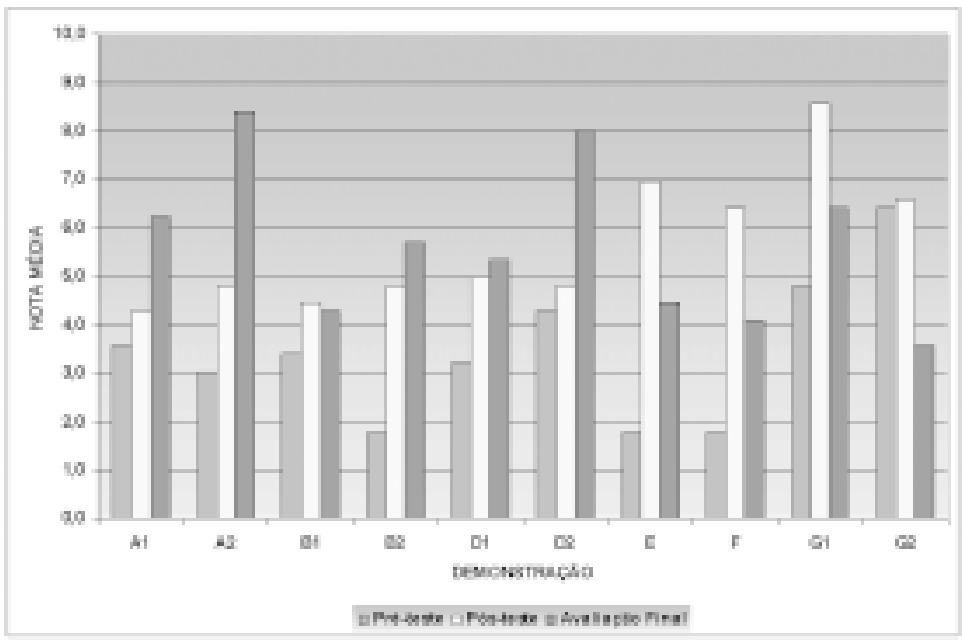

Gráfico 1: N ota média da turma relativa a cada demonstração nos três instrumentos utilizados

\section{Considerações finais}

O uso do vídeo D emonstrações sobre C onceitos de Físca T érmica em sala de aula pode atender à necessidade de material didático estruturado que apresente fenômenos físicos com evidência, diferente dos esquemas e diagramas estáticos em páginas de livros didáticos ou desenhados em quadros-negros, e diferente de vídeos longos, em geral reprodutores da aula do professor (telecurso). 
O estudo da aplicação do vídeo como O rganizador Prévio Experimental (OPE) mostrou que existe um efeito positivo para construção de conceitos básicos, que pode estar associado não somente ao vídeo, mas também às suas características e à forma proposta de utilização.

Alguns alunos são factuais em suas respostas, quando alegam, por exemplo, que "o ar quente sobe", e consideram essa justificativa definitiva para explicar a existência das correntes de convecção térmica. U m aluno, por exemplo, só parece ter aprendido que a massa de um corpo é constante com a variação de temperatura na demonstração sobre dilatação térmica e não na demonstração sobre calor como matéria: "o aquecimento muda o tamanho do corpo, mas a massa permanece constante".

$\mathrm{N}$ em sempre os alunos fazem uso das informações contidas em uma demonstração, o que aponta para dificuldade dos estudantes no processo de observação, que não pode ser imposto, mas sim construído. Por este motivo considerase importante um roteiro de acompanhamento quando se assiste a um vídeo didático.

A área de Física Térmica, considerada por muitos professores como de mais fácil compreensão, apresenta conceitos difíceis de serem modelados, já que as concepções espontâneas estão arraigadas na estrutura cognitiva do aluno, como, por exemplo, a ideia do calor contido em um corpo ou a ideia de que a temperatura é a medida do calor.

O uso de um vídeo didático exige do professor habilidades que promovam condições para que os alunos reflitam sobre o que assistiram de modo a tornar aquilo que foi visto em algo aprendido, utilizando recursos como congelar a imagem, repetir a exibição com outro ritmo, observar reiteradamente alguns planos, entre outros.

A forma de utilização de um vídeo didático é tão importante quanto o próprio vídeo, devendo sempre estar articulada com a proposta educativa. $\mathrm{N}$ esse sentido, as características de determinado vídeo devem ser levadas em consideração para sua utilização. 
O vídeo $D$ emonstrações sobre $C$ onceitos de Física Térmica proporciona diferentes de possibilidades de uso, facilitando sua apropriação por outros professores nos mais diversos contextos. Ele pode ser entendido como um tipo de "pau para toda obra", o qual o professor insere onde e como quiser em sua prática a fim de conseguir um ponto de apoio, completar um vazio ou formalizar um ensinamento, entre outros.

R ecomenda-se o uso do vídeo com o Guia de Acompanhamento, através de uma sequência: observação $\rightarrow$ registro $\rightarrow$ pergunta $\rightarrow$ explicação.

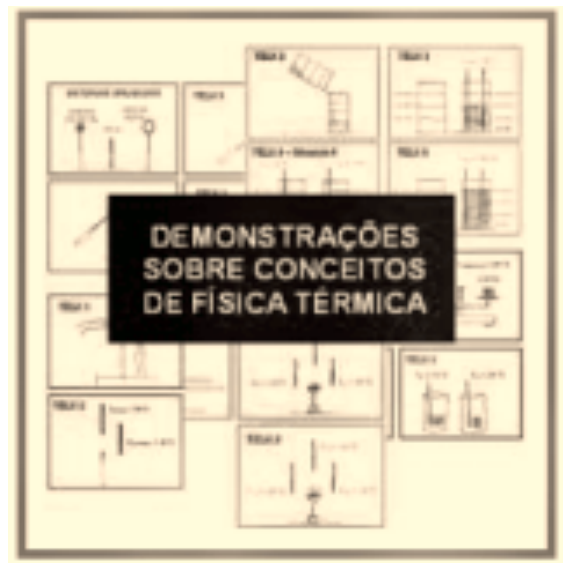

Figura 8: Título do vídeo tendo como fundo o roteiro storyboard das cenas

A seguir, algumas sugestões de estratégias de utilização do vídeo:

1. Organizador Prévio Experimental (OPE): utilização de todas as demonstrações antes da apresentação formal dos conteúdos, a fim de criar um arcabouço que poderá servir para sustentação dos novos conceitos.

2. Ilustração da Teoria (IT): as demonstrações podem ser utilizadas seletivamente, à medida que o professor apresenta novos conceitos quando progride no programa escolar;

3. Estudo Independente (EI): os estudantes assistem às demonstrações, sem a intervenção do professor, em casa (com o 
uso de um DVD player ou computador), ou no laboratório de informática da escola;

4. Ensinoa D istância (EAD ): o Guia de A companhamento pode ser adaptado para um roteiro de ensino a distância e o vídeo utilizado como material EAD.

$\mathrm{N}$ ão há uma receita única para o uso do vídeo. O s professores devem se apossar do material audiovisual e utilizá-lo da forma que desejarem. N o Brasil, o vídeo didático ainda não é entendido como uma estratégia que pode contribuir para o processo de ensino-aprendizagem de ciências através do uso sistemático e controlado dessa tecnologia.

A solução para a melhoria do ensino de Física no Brasil está relacionada à conjugação de vários esforços, bem aquém da simples utilização de um vídeo. $\mathrm{N}$ ão se defende o uso do vídeo como a solução das dificuldades dos estudantes, mas sim o enriquecimento do planejamento do professor com a utilização desse material.

A utilização do vídeo produzido se mostrou eficaz como uma estratégia alternativa para promoção da aprendizagem conceitual mais adequada da Física Térmica, contribuindo para a etapa de instrução, na qual os alunos faziam referências às imagens vistas quando aprendiam formalmente os conceitos trabalhados nas demonstrações.

A produção de vídeos de demonstrações experimentais curtas e simples deve ser estimulada, pois pode gerar um acervo disponível publicamente, enriquecendo o trabalho dos professores e o aprendizado dos alunos.

\section{Referências}

AU SU BEL , D avid. E ducational Psychology: a CognitiveV iew. N ew York, USA: H olt R inehart and W inston, 1968.

BRASI L . M EC/SEB. M inistério da E ducação. Secretaria de E ducação Básica. Parâmetros C urriculares $\mathrm{N}$ acionais para o Ensino M édio - C iências 
da $\mathrm{N}$ atureza, $\mathrm{M}$ atemática esuasTecnologias. B raślia: M inistério da E ducação, 2000. D isponível em: < http://portal.mec.gov.br/seb/arquivos/pdf/ ciencian.pdf>. A cesso em 31 julho 2008.

CO LIN VAU X, D ominique; BAR R OS, Susana deSouza. O Papel da M odelagem no L aboratório D idático de Física: 0 que há para se aprender? In: A naisdoVIII EncontrodePesquisa em Ensino deFísica, 2002. Águas de L indóia. São Paulo: SBF, 2002.

FER R É S, Joan. Vídeo e Educação. Porto Alegre: Artes M édicas, 2. ed., 1996.

FI LIPECK I, A na Tereza; BAR R OS, Susana de Souza. U ma nova estratégia para o laboratório de Física no 2ํo grau: elaboração de vídeos pelos estudantes. In: A naisdo II Encontro $\mathrm{N}$ acional dePesquisa em E ducação em Ciências, 1999, Valinhos. Porto Alegre: ABRAPEC, 1999.

LU NETTA, V incent. TheSchool Science L aboratory: H istorical Perspectives and Contexts for Contemporary Teachers. In: FRASER, B. J. \& TO BIN , K. G. (Eds.). I nternational H andbook of ScienceEducation (Part O ne). D ordrecht: K luwer A cademic Publishers, p. 249-262, 1998.

PER EIRA, M arcusV inicius; FI LIPECKI , A naTereza; BAR R OS, Susana deSouza. D emonstrações Controladas de FenômenosT érmicos Gravadas em Vídeo. In: A naisdoX VI SimpósioN acional deEnsino deFísca, 2005. Rio de J aneiro. São Paulo: SBF, 2005.

PRETTO, N elson de L ucca. U ma Escola sem/com Futuro: educação emultimídia, 6. ed. Campinas, SP: Papirus, 2005.

R eorientação C urricular para o Estado do R io de Janeiro. D isponível em: < http://www.limc.ufrj.br/curriculo.htm>. Acesso em 31 jul. 2008.

\section{Anexo I: Pré/Pós-Teste}

1. O calor é um conceito físico que tem natureza de: (Justifique sua escolha)

( ) matéria

( ) energia

( ) temperatura 
2. Em um recipiente há 10 bolinhas metálicas, todas à temperatura ambiente de $30^{\circ} \mathrm{C}$. Se retirarmos uma dessas bolinhas, qual será a sua temperatura? J ustifique.
( ) $3 \circ \mathrm{C}$
( ) $30 \circ \mathrm{C}$
( ) $300^{\circ} \mathrm{C}$

3. O que acontece quando você mistura quantidades iguais de água, uma bem fria a uma temperatura T 1 e outra bem quente a uma temperatura T2? Justifique.

( ) cada massa de água permanece à temperatura inicial

( ) a mistura atinge uma temperatura chamada de equilíbrio térmico próxima de $(\mathrm{T} 1+\mathrm{T} 2) / 2$

( ) a mistura atinge uma temperatura chamada de equilíbrio térmico que é igual a (T 1+T2)

4. Que tipo de colher presente em uma cozinha deve ser escoIhida para mexer uma panela onde se cozinhará um doce de banana? J ustifique.
( ) colher de madeira
( ) colher de metal
( ) colher de plástico

5. Dois pedaços de um mesmo metal estão quentes e à mesma temperatura. U m deles tem o dobro do tamanho do outro, e, consequentemente, o dobro da massa. Se cada um for colocado em um copo distinto que contém a mesma quantidade de água, 0 que você pode concluir sobre a variação da temperatura água + metal? J ustifique.

( ) é a mesma nos dois copos

( ) será maior no copo que recebeu o pedaço menor

( ) será maior no copo que recebeu o pedaço maior

6. 0 que você faria para abrir um tampo metálico rosqueado que se encontra muito justo em um recipiente de vidro, por exemplo os que acondicionam palmito, azeitona, conservas, etc.? Justifique. 
( ) usaria um objeto como alavanca para fazer força contra a tampa

( ) aqueceria a tampa, que poderia ficar frouxa em relação ao vidro

( ) usaria um pano eforçaria a abertura da tampa rosqueada

7. Q ual éa melhor posição para instalar um aparelho de ar acondicionado em uma sala que fica fechada? Justifique.

( ) próximo ao teto

( ) próximo ao chão

( ) não faz diferença

8. Se usarmos um martelo e o batermos sucessivas vezes sobre uma pequena moeda: (Justifique sua escolha)

( ) a moeda apenas se deformará

( ) a moeda não se modifica fisicamente

( ) a moeda poderá ficar mais quente, além de poder se deformar

9. U ma panela de água fervendo foi derramada em uma piscina olímpica cheia de água à temperatura em torno de 25으. Q ual será a temperatura aproximada da água na piscina? J ustifique.

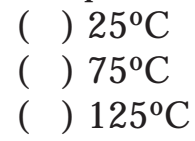

10. O que você pode afirmar sobre a temperatura de um líquido contido em uma panela sobre a chama de um fogão que ficará acesa indefinidamente? J ustifique.

( ) a temperatura aumenta indefinidamente

( ) a temperatura aumenta até um valor limite para o líquido e permanece constante

( ) a temperatura aumenta até um valor limite para o líquido e depois começa a diminuir 